\title{
Influenza vaccination during the coronavirus pandemic: intention to vaccinate among the at-risk population in the Central Catalonia Health Region (VAGCOVID)
}

\author{
Anna Bonet-Esteve ${ }^{1,2}$, Raquel Muñoz-Miralles ${ }^{3 *}$, Carla Gonzalez-Claramunt ${ }^{4}$, Ana M Rufas ${ }^{5}$, \\ Xavier Pelegrin Cruz $^{6}$ and Josep Vidal-Alaball ${ }^{2,7,8}$
}

\begin{abstract}
Background: Influenza is a major public health issue, with the primary preventive measure being an annual influenza vaccination. Nevertheless, vaccination coverage among the at-risk population is low. Our understanding of the behaviour of the influenza virus during the SARS-CoV-2 coronavirus pandemic is limited, meaning influenza vaccination is still recommended for individuals at risk for severe complications due to influenza infection. The aim of the study is to determine the intention to vaccinate against seasonal influenza among the at-risk population in the 202021 campaign during the SARS-CoV-2 pandemic and to analyse the factors which influence such intention.

Methods: Cross-sectional telephone survey of adults (aged over 18) with risk factors in central Catalonia where the need for the Seasonal Influenza Vaccine (SIV) was recommended.

Results: A total of 434 participants responded to the survey, $43.3 \%$ of whom intended to be vaccinated against influenza for the 2020-2021 influenza season, 40.8\% had no intention to be vaccinated and $15.9 \%$ were uncertain or did not express their opinion. The intention to get vaccinated against influenza is associated with having dependents, the individual's perception of the risk of being infected with influenza and the perceived risk of transmission to dependents. It is also associated with age, whether the individual had received influenza vaccine the previous season or any other season before. The best predictors of the intention to vaccinate are the individual's perception of the risk of catching influenza and whether the individual had been vaccinated in the previous season.

Conclusions: Intention to vaccinate can be a good predictor of individual behaviour in relation to vaccination. During the current SARS-CoV-2 pandemic many individuals are hesitant to influenza vaccination. In order to improve influenza vaccination coverage in people included in risk groups, it is necessary to promote educational actions, especially among those who express doubts.
\end{abstract}

Keywords: Human influenza, Influenza vaccines, Intention, COVID-19, Health Knowledge, Attitudes, Practice, Vaccination refusal, Vaccination coverage

\footnotetext{
*Correspondence: rmunozm.cc.ics@gencat.cat

${ }^{3}$ Centre d'Atenció Primària Plaça Catalunya, SAP Bages-Berguedà-

Solsonès, Gerència Territorial Catalunya Central Institut Català de la Salut,

CAP Plaça Catalunya. C/ Soler i March 6, 08242 Manresa, Spain

Full list of author information is available at the end of the article
}

(C) The Author(s) 2021. Open Access This article is licensed under a Creative Commons Attribution 4.0 International License, which permits use, sharing, adaptation, distribution and reproduction in any medium or format, as long as you give appropriate credit to the original author(s) and the source, provide a link to the Creative Commons licence, and indicate if changes were made. The images or other third party material in this article are included in the article's Creative Commons licence, unless indicated otherwise in a credit line to the material. If material is not included in the article's Creative Commons licence and your intended use is not permitted by statutory regulation or exceeds the permitted use, you will need to obtain permission directly from the copyright holder. To view a copy of this licence, visit http://creativecommons.org/licenses/by/4.0/. The Creative Commons Public Domain Dedication waiver (http://creativeco mmons.org/publicdomain/zero/1.0/) applies to the data made available in this article, unless otherwise stated in a credit line to the data. 


\section{Background}

Influenza becomes a major public health problem every year as a result of the high rates of morbidity which occur during the successive waves of the epidemic and the presence of complications and excess mortality in specific population groups [1,2].

It is estimated that influenza can affect between $5 \%$ and $20 \%$ of the general population and $50 \%$ of institutionalized populations. In previous years, it is estimated that up to $25 \%$ of acute febrile respiratory conditions could be caused by the influenza virus in Catalonia. This symptomatology generates a significant number of medical consultations and workday loss as a result of the disease and its convalescence, which can last from a few days to a few weeks [1].

In some cases, the disease can become more severe due to the influenza virus or a secondary, usually bacterial, infection which most commonly manifests itself as pneumonia, and may even prove fatal. At other times it can present in the form of cardiovascular disease, myocarditis or encephalitis, which can also be fatal. Nevertheless, frequently the initial influenza infection goes undiagnosed and is not usually recorded as the cause of death in death certificates. Overall influenza-associated mortality has been estimated to 13.8 per 100,000 person-years in Europe. Complications can occur in anyone, although hospitalizations are more common in the elderly ( $\geq 65$ years, $309 / 100,000$ person-years $)$ and in young children $(<1$ year, 151/100,000 person-years) [3].

Influenza virus is transmissible from one day before the onset of symptoms to 4 days after. Although young children and people with weakened immune systems, might be able to infect others for a longer time. Between 30\% and $50 \%$ of individuals infected with the influenza virus may be asymptomatic, though they may pass it on to others through respiratory droplets [4].

The Seasonal Influenza Vaccine (SIV) is the primary preventive measure to prevent influenza and its complications $[1,5]$. In Catalonia and most neighbouring countries, it is generally recommended for at-risk populations, that is, people with underlying conditions or personal circumstances that make them more susceptible to complications or decompensation, leading hospital admissions and higher mortality rate [6].

In the Northern Hemisphere, vaccines are administered in early autumn, before the winter season begins [7]. Since the level of vaccine coverage tends to be low among the general population, due to both the strategy of specifically recommending vaccinations to the at-risk population and the low coverage achieved in this group, it is difficult for the SIV to achieve a significant decrease in influenza incidence in the community.
SIV coverage in Catalonia during the 2018-19 influenza vaccination campaign for people aged 65 years and older was $51 \%$, similar to that of Spain (54.3\%), yet in those under 60 years it was only $15.86 \%$ [1]. In people aged 60 to 64 and pregnant women the coverage was $20 \%$ and $29.2 \%$ respectively. In Spain, on the other hand, coverage was $22.3 \%$ in the $60-64$ age group and $40.6 \%$ in pregnant women [8].

Influenza vaccination coverage rates fall a long way short from the $75 \%$ target proposed by the World Health Organization (WHO) and the European Centre for Disease Prevention and Control (ECDC). For the 2020-21 influenza vaccination campaign in Catalonia and Spain, the goal has been set to achieve or exceed $75 \%$ of vaccinations in people aged over 65 and in healthcare professionals, and $60 \%$ in pregnant women and people with a high risk for complications $[6,9]$.

According to a review of 48 articles on SIV [10], the main barriers to vaccination among the general population and even among health professionals are lack of awareness and knowledge of influenza and misconceptions about the disease and the vaccine used in its prevention.

With respect to the current SARS-CoV-2 pandemic, the 2020-21 SIV campaign is expected to be influenced by a lack of knowledge as to the behaviour of the influenza virus and the risk of coinfection by both viruses. For this reason, health authorities support an increase in SIV coverage among at-risk groups in order to reduce the number of cases which occur during the peak of the influenza season and their impact on the healthcare system $[6,9]$.

Behaviour, seen as a set of individual or collective actions, is a fundamental factor which influences human health. Certain behaviours related to health or illness are difficult to modify since, although they may not be unhealthy, they are thoroughly entrenched in individuals or groups. According to Ecological Systems Theory, changes in behaviour with respect to vaccination, depend on numerous factors which influence it: personal factors which make an individual accept or reject a vaccine, and also the sociocultural factors and the broader geographical and temporal context in which they live [11].

According to Ajzen's Theory of Planned Behaviour $[11,12]$, intention is a key determinant of action. For this reason, it is important to find out what the at-risk population's intentions are with respect to the SIV during the current SARS-CoV-2 pandemic [13]. Also, it is relevant to examine whether the protective measures put in place to mitigate COVID-19 transmission can influence individuals in their decision to get vaccinated against influenza [14]. 
The aim of the study is to determine the at-risk population's intention to vaccinate against seasonal influenza during the 2020-21 flu campaign in the Central Catalonia Health Region, in the midst of the SARS-CoV-2 pandemic. The specific objectives of the study are: 1 ) To assess the perception of the risk of catching seasonal influenza during the SARS-CoV-2 pandemic. 2) To determine whether contextual factors related to the increased physical and hygiene protective measures put in place during the pandemic [14] influence the intention to be vaccinated against influenza.

\section{Methods}

This is a cross-sectional study on the intention to receive the influenza vaccine and risk perception of contracting seasonal influenza during the SARS-CoV-2 pandemic in a sample of the at-risk population by means of a telephone survey. The influence of the contextual factors related to increased hygiene/physical measures during the pandemic were also evaluated. The questionnaire used (Additional file 1) is based on an earlier survey conducted by Apiñaniz to study the acceptability of an influenza $A(H 1 N 1)$ vaccine [15].

The study was conducted in the Central Catalonia Health Region, which includes the counties of Anoia, Bages, Berguedà, Moianès and Osona. The duration of the study was from October 1 to 15, 2020,15 days before the start of the influenza vaccination campaign .The study population is made up of those individuals registered at the Primary Care Teams (PCTof the Catalan Institute of Health of Central Catalonia, consisting of approximately 400,000 individuals.

The inclusion criteria were: 1) Individuals aged over 18 years. 2) Eligible for influenza vaccination because of their at-risk group condition (people with underlying illnesses which make them more susceptible to complications or decompensations) (Table 1) [5]. 3) To have given written authorization to be contacted by telephone to receive health information. 4) To have given informed consent to participate in the study on a voluntary basis.

The exclusion criteria were: 1) A language barrier. 2) Incorrect phone number or failure to answer a call after a maximum of two attempts at different times. 3) Individuals who were uncapable of understanding the nature of the study. 4) Individuals living in institutions.

The sample size was calculated using the GRANMO calculation programme [16]. It was calculated that a random sample of 427 individuals was sufficient to estimate, with a $95 \%$ confidence level and a margin of error of $+/-5 \%$, a population percentage which is expected to be around $51 \%$. The replacement rate was estimated to be $10 \%$.
Table 1 Priority groups for influenza vaccination

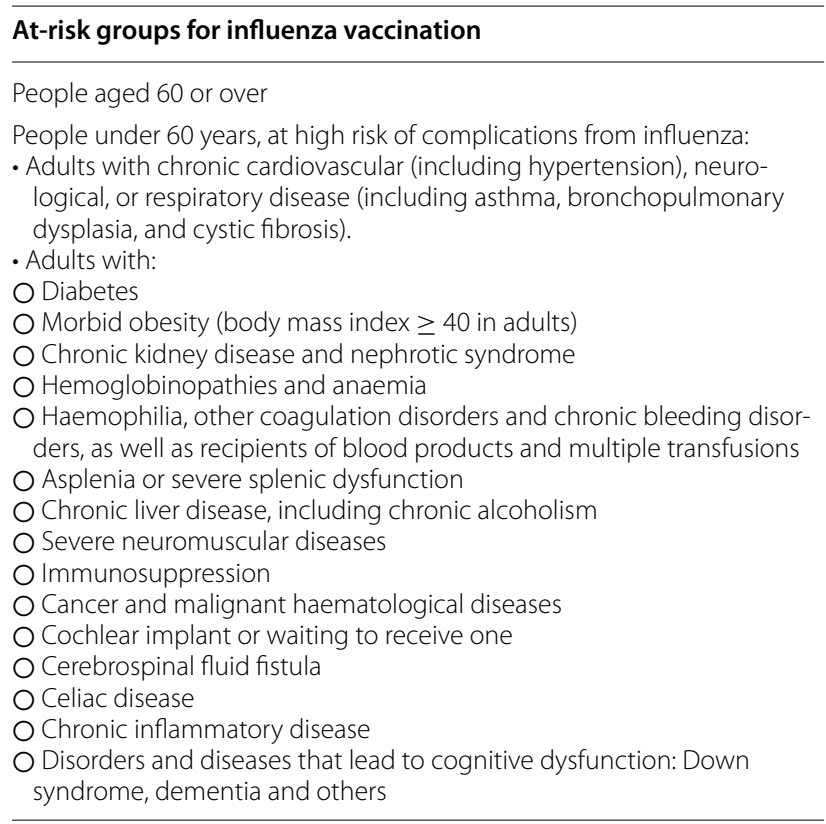

The telephone survey of participants was conducted by four interviewers who had previously attended a training session for standardisation purposes and to avoid differences in the interpretation of the answers. A randomized list of individuals belonging to the study group was made available and those who met the inclusion criteria were included, until the number of participants required for the sample was obtained.

A descriptive statistical analysis was performed on the data resulting from the answers to the questionnaire. Categorical variables were described using frequencies and percentages. Continuous variables were described with mean and standard deviation. The proportions of categorical variables were compared using Fisher's exact test or Pearson's chi-square test and the t-test for continuous variables. The best fit model for logistic regression was used to predict intention to vaccinate using the Bayesian Information Criterion, only taking into account variables with significant association with intention to vaccinate For later validation of the model, the data were split into the training set $(80 \%)$ and the validation set $(20 \%)$.

The R Project for Statistical Computing for Windows (version 3.6.3) was used for statistical analysis. In the resulting data that were unrepresentative, levels were simulated or eliminated in order to obtain an approximate $p$-value. Results with a $p$-value higher than 0.05 $(p<0.05)$ were considered statistically significant.

The study protocol was approved by the University Institute for Primary Care Research (IDIAP) Jordi Gol Health Care Ethics Committee (Code 20/177-PCV). 


\section{Results}

A total of 434 individuals with risk factors were interviewed of whom 258 (59.4\%) were women. The average age of the respondents was 60 years, with an age range between 20 and 100, and $152(35 \%)$ were under 60 years old. Four hundred and five (93.3\%) participants were of Spanish origin and 206 (47.5\%) were educated to primary level. Three hundred and seven participants $(70.7 \%)$ lived with a partner and 217 (50.0\%) were retired (Table 2).
Fifty four (12.4\%) participants had children at their care and $51(11.8 \%)$ cared for a dependent person. Of these, $34(32.4 \%)$ were of the opinion that this year the individuals at their care had a high risk of catching influenza, while 49 (46.7\%) participants believed that they did not. One hundred and fifty-five (35.7\%) respondents had been vaccinated against influenza the previous year and $216(49.8 \%)$ had been vaccinated in another season (Table 3).

Table 2 Participants' influenza vaccination intention and sociodemographic characteristics

\begin{tabular}{|c|c|c|c|c|c|}
\hline VARIABLE & Yes & No & DK/NO & Total & $p$ \\
\hline Intention to have SIV & $188(43.3)$ & 177 (40.8\%) & $69(15.9 \%)$ & $434(100 \%)$ & \\
\hline Gender & & & & & 0.811 \\
\hline Male & 79 (44.9\%) & $71(40.3 \%)$ & $26(14.8 \%)$ & $176(40.6 \%)$ & \\
\hline Female & 109 (42.2\%) & $106(41.1 \%)$ & $43(16.7 \%)$ & $258(59.4 \%)$ & \\
\hline Other & $0(0 \%)$ & $0(0 \%)$ & $0(0 \%)$ & $0(0 \%)$ & \\
\hline Age & & & & & $<0.001$ \\
\hline Average & 65 (12.8) & $58(12.2)$ & $60(13.7)$ & & \\
\hline \multicolumn{6}{|l|}{ Age by group } \\
\hline$<60$ & $42(27.6 \%)$ & $82(53.9 \%)$ & $28(18.4 \%)$ & $152(35.0 \%)$ & \\
\hline $60-70$ & $82(45.1 \%)$ & $73(40.1 \%)$ & $27(14.8 \%)$ & $100(23.0 \%)$ & \\
\hline$>70$ & $64(64.0 \%)$ & $22(22.0 \%)$ & $14(14.0 \%)$ & $182(41.9 \%)$ & \\
\hline Origin & & & & & 0.245 \\
\hline Spanish national & $171(42.2 \%)$ & $168(41.5 \%)$ & $66(16.3 \%)$ & 405 (93.3\%) & \\
\hline Foreigner & $17(58.6 \%)$ & $9(31.0 \%)$ & $3(10.3 \%)$ & $29(6.7 \%)$ & \\
\hline Education level & & & & & $0.016^{*}$ \\
\hline No studies & $12(63.2 \%)$ & $3(15.8 \%)$ & $4(21.1 \%)$ & $19(4.4 \%)$ & \\
\hline Primary level & 98 (47.6\%) & 72 (35.0\%) & $36(17.5 \%)$ & $206(47.5 \%)$ & \\
\hline Secondary level & $42(33.6 \%)$ & $63(50.4 \%)$ & $20(16.0 \%)$ & $125(28.8 \%)$ & \\
\hline Higher education & $35(42.2 \%)$ & $39(47.0 \%)$ & $9(10.8 \%)$ & $83(19.1 \%)$ & \\
\hline DK/NO & $1(100 \%)$ & $0(0 \%)$ & $0(0 \%)$ & $1(0.2 \%)$ & \\
\hline Marital status & & & & & 0.697 \\
\hline Single & $14(36.8 \%)$ & $18(47.4 \%)$ & $6(15.8 \%)$ & $38(8.8 \%)$ & \\
\hline Married/living with a partner & $132(43.0 \%)$ & $124(40.4 \%)$ & $51(16.6 \%)$ & $307(70.7 \%)$ & \\
\hline Separated/divorced & $15(40.5 \%)$ & $18(48.6 \%)$ & $4(10.8 \%)$ & $37(8.5 \%)$ & \\
\hline Widow(er) & 27 (51.9\%) & 17 (32.7\%) & $8(15.4 \%)$ & 52 (12.0\%) & \\
\hline Employment status & & & & & $<0.001^{*}$ \\
\hline Member of a cooperative & $2(66.7 \%)$ & $1(33.3 \%)$ & $0(0 \%)$ & $3(0.7 \%)$ & \\
\hline Employer with employees & $3(30.0 \%)$ & $5(50.0 \%)$ & $2(20.0 \%)$ & $10(2.3 \%)$ & \\
\hline Self-employed or employer with no employees & $5(26.3 \%)$ & $12(63.2 \%)$ & $2(10.5 \%)$ & $19(4.4 \%)$ & \\
\hline Working for the family company/business & $1(20.0 \%)$ & $4(80.0 \%)$ & $0(0 \%)$ & $5(1.2 \%)$ & \\
\hline Public sector employee & $8(25.0 \%)$ & $14(43.8 \%)$ & $10(31.2 \%)$ & $32(7.4 \%)$ & \\
\hline Private sector employee & $29(35.5 \%)$ & $52(59.1 \%)$ & $7(7.95 \%)$ & $88(20.3 \%)$ & \\
\hline Unemployed & $11(35.5 \%)$ & $12(38.7 \%)$ & $8(25.8 \%)$ & $31(7.1 \%)$ & \\
\hline On furlough & $1(100 \%)$ & $0(0 \%)$ & $0(0 \%)$ & $1(0.2 \%)$ & \\
\hline Retired & $117(53.9 \%)$ & $67(30,9 \%)$ & $33(15.2 \%)$ & $217(50.0 \%)$ & \\
\hline Other & $11(39.3 \%)$ & $10(35.7 \%)$ & $7(25.0 \%)$ & $28(6.5 \%)$ & \\
\hline Dependents & & & & & 0.005 \\
\hline Children (under 14 years of age) & $15(27.8 \%)$ & $29(53.7 \%)$ & $10(18.5 \%)$ & $54(12.4 \%)$ & \\
\hline Person with physical and/or mental disability $>60$ years old & $19(37.3 \%)$ & $17(33.3 \%)$ & $15(29.4 \%)$ & $51(11.8 \%)$ & \\
\hline None & $154(46.8 \%)$ & 131 (39.8\%) & $44(13.4 \%)$ & 329 (75.8\%) & \\
\hline
\end{tabular}


Table 3 Vaccination intention according to perception of risk of catching influenza, number of risk factors and vaccination history

\begin{tabular}{|c|c|c|c|c|c|}
\hline Perception of risk of dependents catching influenza & & & & & 0.034 \\
\hline Yes & $15(44.1 \%)$ & $9(26.5 \%)$ & $10(29.4 \%)$ & $34(32.38 \%)$ & \\
\hline No & $15(30.6 \%)$ & $27(55.1 \%)$ & $7(14.3 \%)$ & $49(46.66 \%)$ & \\
\hline DK/NO & $4(18.2 \%)$ & $10(45.5 \%)$ & $8(36.4 \%)$ & $22(20.9 \%)$ & \\
\hline Perception of the risk of personally catching influenza & & & & & $<0.001$ \\
\hline Yes & $88(71.0 \%)$ & $18(14.5 \%)$ & $18(14.5 \%)$ & $124(28.6 \%)$ & \\
\hline No & $52(25.6 \%)$ & $121(59.6 \%)$ & $30(14.8 \%)$ & $203(46.8 \%)$ & \\
\hline DK/NO & $48(44.9 \%)$ & $38(35.5 \%)$ & $21(19.6 \%)$ & $107(24.7 \%)$ & \\
\hline \multirow[t]{2}{*}{ No. of risk factors (including age) } & & & & & $<0.001$ \\
\hline & $2.23(1.26)$ & $1.51(0.92)$ & $1.64(1.03)$ & $1.84(1.14)$ & \\
\hline \multirow[t]{2}{*}{ No. of risk factors (not including age) } & $N=41$ & $N=82$ & $N=28$ & $N=151$ & 0.070 \\
\hline & $1.34(0.57)$ & $1.11(0.44)$ & $1.25(0.70)$ & $1.20(0.542)$ & \\
\hline Vaccinated the previous year & & & & & $<0.001$ \\
\hline Yes & $138(89.0 \%)$ & $3(1.94 \%)$ & $14(9.03 \%)$ & $155(35.7 \%)$ & \\
\hline No & $47(17.1 \%)$ & $174(63.3 \%)$ & $54(19.6 \%)$ & $275(63.4 \%)$ & \\
\hline DK/NO & $3(75.0 \%)$ & $0(0 \%)$ & $1(25.0 \%)$ & $4(0.9 \%)$ & \\
\hline Vaccinated on other occasions & & & & & $<0.001$ \\
\hline Yes & $149(69.0 \%)$ & $35(16.2 \%)$ & $32(14.8 \%)$ & $216(49.8 \%)$ & \\
\hline No & $39(17.9 \%)$ & $142(65.1 \%)$ & $37(17.0 \%)$ & $218(50.2 \%)$ & \\
\hline DK/NO & $0(0 \%)$ & $0(0 \%)$ & $0(0 \%)$ & $0(0 \%)$ & \\
\hline
\end{tabular}

One hundred and eighty-eight (43.3\%) participants reported intention to be vaccinated against influenza this season, 177 (40.8\%) had no intention to be vaccinated and 69 (15.9\%) did not know yet or did not answer. When asked if they intended to be vaccinated against influenza due to the context of $\mathrm{d}$ the SARS-CoV-2 pandemic, 212 (48.8\%) answered that they did, 34 (7.8\%) of whom would do so due to the pandemic and 178 (41.0\%) intended to receive the vaccine regardless the context. However, $71(16.4 \%)$ were hesitant or didn't answer the question (Table 4). Of all those who intended to be vaccinated against influenza, $14.9 \%$ would do it due to the pandemic.

Regarding vaccination intention and the relationship with the protective measures put in place during the pandemic, 156 (36.6\%) reported they will be vaccinated despite wearing face masks and $47(10.8 \%)$ said they won't do so because they believe that masks already protected them. Regarding hand washing and physical distancing, $162(37.3 \%)$ and 157 (36.2\%) respondents respectively stated that they will be vaccinated despite following these measures. Fifty participants $(11.5 \%)$ do not intend to be vaccinated because they believed that hand washing already protected them and 56 (12.9\%) said they won't be vaccinated due to the protection afforded by physical distancing. Aproximately $25 \%$ of respondents had no intention of getting vaccinated despite acknowledging that none of the three measures protected them. Regarding the questions related to the three contextual variables, the response Don't Know/No Opinion was chosen by $20 \%$ of the participants.

Those under 60 years of age expressed a significantly lower intention to be vaccinated than those over 60 years of age $(p<0.001)$. Retired participants were more in favour of being vaccinated compared with those actively working $(p<0.001)$. Living with dependents (children and adult dependents) was strongly associated with the intention to vaccinate $(p<0.005)$. The intention to vaccinate was also related to the perception of the risk of catching influenza $(p<0.001)$ and to the perceived risk for transmission to dependent individuals $(p$ $=0.03$ ). Those with lower levels of education were more inclined to be vaccinated than those with higher education $(p=0.016)$.

Having risk factors, excluding age, was not associated with vaccination intention $(p=0.07)$. With regard to an individual's history of influenza vaccinations, the intention to vaccinate this year was associated with having been vaccinated the previous year and on another earlier season $(p<0.001)$. Neither gender, nationality, nor marital status showed statistically significant differences with respect to the respondents' intention to vaccinate. However, a relationship was found with their level of education and employment status.

The best logistic regression model for predicting the intention to vaccinate took into account just two variables: the subject's perception of whether they would catch influenza and whether or not they had been vaccinated 
Table 4 Vaccination intention in light of the SARS-CoV-2 pandemic

\begin{tabular}{|c|c|c|c|c|c|}
\hline \multicolumn{5}{|l|}{ COVID-19 pandemic and vaccination intention } & \multirow[t]{2}{*}{$<0.001$} \\
\hline Yes, regardless of the COVID-19 pandemic & $154(86.5 \%)$ & $17(9.55 \%)$ & $7(3.93 \%)$ & $178(41.0 \%)$ & \\
\hline Yes, due to the COVID-19 pandemic & $27(79.4 \%)$ & $1(2.94 \%)$ & $6(17.6 \%)$ & $34(7.8 \%)$ & \\
\hline No, in spite of the COVID-19 pandemic & $0(0 \%)$ & $32(97.0 \%)$ & $1(3.03 \%)$ & $33(7.6 \%)$ & \\
\hline No, regardless of the COVID-19 pandemic & $4(3.39 \%)$ & $111(94.1 \%)$ & $3(2.54 \%)$ & $118(27.2 \%)$ & \\
\hline DK/NO & $3(4.23 \%)$ & $16(22.5 \%)$ & $52(73.2 \%)$ & $71(16.4 \%)$ & \\
\hline Mask usage and vaccination intention & & & & & $<0.001$ \\
\hline I will get vaccinated, even though masks offer protection, & $151(95.0 \%)$ & $1(0.63 \%)$ & $7(4.40 \%)$ & $159(36.6 \%)$ & \\
\hline I will get vaccinated as masks don't offer protection & $28(93.3 \%)$ & $0(0 \%)$ & $2(6.67 \%)$ & $30(6.9 \%)$ & \\
\hline Masks don't offer protection, but I won't get vaccinated & $0(0 \%)$ & $110(99.1 \%)$ & $1(0.90 \%)$ & $111(25.6 \%)$ & \\
\hline Masks offer protection, which is why I won't get vaccinated & $2(4.26 \%)$ & $44(93.6 \%)$ & $1(2.13 \%)$ & $47(10.8 \%)$ & \\
\hline DK/NO & $7(8.05 \%)$ & $22(25.3 \%)$ & $58(66.7 \%)$ & $87(20.0 \%)$ & \\
\hline Hand washing and vaccination intention & & & & & $<0.001$ \\
\hline I will get vaccinated, even though hand washing offers protection. & $154(95.1 \%)$ & $1(0.62 \%)$ & $7(4.32 \%)$ & $162(37.3 \%)$ & \\
\hline I will get vaccinated as hand washing doesn't offer protection & $24(88.9 \%)$ & $0(0 \%)$ & $3(11.1 \%)$ & $27(6.2 \%)$ & \\
\hline I won't get vaccinated, even though hand washing doesn't offer protection & $0(0 \%)$ & $106(98.1 \%)$ & $2(1.85 \%)$ & $108(24.9 \%)$ & \\
\hline I won't get vaccinated as hand washing offers protection & $1(2.0 \%)$ & $49(98.0 \%)$ & $0(0 \%)$ & $50(11.5 \%)$ & \\
\hline DK/NO & $9(10.3 \%)$ & $21(24.1 \%)$ & $57(65.5 \%)$ & $87(20.0 \%)$ & \\
\hline Physical distancing and vaccination intention & & & & & $<0.001$ \\
\hline Social distancing offers protection, I will get vaccinated & $152(96.8 \%)$ & $0(0 \%)$ & $5(3.18 \%)$ & $157(36.2 \%)$ & \\
\hline Social distancing doesn't offer protection, which is why I will get vaccinated & $24(80.0 \%)$ & $1(3.33 \%)$ & $5(16.7 \%)$ & $30(6.9 \%)$ & \\
\hline Social distancing doesn't offer protection, nevertheless, I won't get vaccinated & $1(0.98 \%)$ & $99(97.1 \%)$ & $2(1.96 \%)$ & $102(23.5 \%)$ & \\
\hline Social distancing offers protection, which is why I will get vaccinated & $1(1.79 \%)$ & 55 (98.2\%) & $0(0 \%)$ & $56(12.9 \%)$ & \\
\hline DK/NO & $10(11.2 \%)$ & $22(24.7 \%)$ & 57 (64.0\%) & $89(20.5 \%)$ & \\
\hline
\end{tabular}

the previous year, obtaining results with a predictive accuracy of $87.7 \%$ (Table 5).

\section{Discussion}

During the current SARS-CoV-2 pandemic, the 202021 Seasonal Influenza Vaccine campaign was perceived to be influenced by a lack of knowledge as to the behaviour of the influenza virus and uncertainty as to the degree of acceptance of SIV by the at-risk population. The health authorities have promoted increased SIV coverage, especially among the elderly and others with risk factors, to protect them and thus to also reduce the strain on the healthcare system $[6,9]$. This study provides data on influenza vaccination intention and the factors which influence the intention in this population group. This makes the study of great value when planning actions aimed at improving SIV coverage in our area.

The results show that the percentage of individuals who intend to get vaccinated against influenza is similar to those who do not intend to do so, though there are also a large number of individuals who remain undecided with regard to this year's influenza vaccination. Therefore, there is the potential for promoting health education among the vaccine hesitant or undecided, if we take into account that, according to Picazo [17], almost 50\% of these who are undecided would be willing to get the vaccine if appropriately explained. Several studies show the possibility of improving vaccine coverage through educational initiatives aimed at individuals who refuse vaccines $[18,19]$.

Table 5 Information on the logistic regression model for vaccination intention in light of the SARS-CoV-2 pandemic as a response variable

\begin{tabular}{|c|c|c|c|c|c|c|}
\hline & $\begin{array}{l}\text { Estimated beta } \\
\text { coefficient }\end{array}$ & Standard deviation & Odds-Ratio & IC 95\% & & $P$-value \\
\hline Intercept & 4.709 & - & - & - & - & - \\
\hline Feel they will catch the influenza $=\mathrm{NO}$ & -1.866 & 0.460 & 0.155 & 0.062 & 0.377 & $<0.001$ \\
\hline Feel they will catch the influenza $=$ DK/NO & -1.281 & 0.520 & 0.278 & 0.097 & 0.757 & 0.014 \\
\hline Vaccinated last year $=\mathrm{NO}$ & -4.631 & 0.621 & 0.010 & 0.002 & 0.028 & $<0.001$ \\
\hline Vaccinated last year $=\mathrm{DK} / \mathrm{NO}$ & 13.078 & 1328.368 & 478084.231 & - & - & 0.992 \\
\hline
\end{tabular}


According to a WHO review of barriers to influenza vaccination [11] there are no conclusive data linking age and vaccine coverage, although this study, along with some others [20], suggests that the elderly are more likely to get vaccinated. Since everyone with risk factors is encouraged to be immunized against influenza, coverage would be expected to be high [20]. Nevertheless, vaccine coverage achieved in previous campaigns [1] together with the data on vaccination intention in our study show that younger people are less vaccinated and have lower vaccination intentions.

A low perception of the risk of influenza is a major barrier to vaccination [13]. The study shows that about half of the respondents have a low perception of the risk of influenza and, in line with other studies [11, 15], this low perception is associated with the intention to refuse being vaccinated. Half of those surveyed with dependents at their care believe there is no risk for their dependents as to being infected with influenza virus and more than half of this group refuse the vaccine. This fact reveals lack of information about the disease, its chains of infections and the possible complications which make the vaccination necessary. As some studies point out, lack of awareness, misconceptions and knowledge gaps are the main barriers to influenza vaccination $[10,11]$.

In line with other studies, vaccination intention for the current season is high in people who were vaccinated the previous season $[11,20]$. This fact shows that a history of previous influenza vaccination is a predictor of vaccination in the current season, especially if it has been a positive experience. With regard to those not vaccinated in the previous year, it is worth noting a considerable increase in the percentage of individuals intending to be vaccinated this year. There was also a significant number of hesitant patients, in keeping with the findings of the Goldman study [13].

The logistical model to predict an individual's vaccination intention shows that, both the perception of catching influenza oneself and an individual's vaccination history for the previous year are variables which favour influenza vaccination coverage, in line with earlier studies $[11,13,20]$. It can be seen that for levels where the response is negative or "Don't know/No Opinion", a negative relationship is maintained with the response to the vaccination intention variable. It is also noteworthy that the "Don't know/No Opinion" responses regarding vaccination in the previous year are insignificant, being almost zero. This should be taken into account in future predictions if the same model is used.

The recent pandemic has meant that users' faceto-face access to health services and communication with health professionals has been impaired. However, organizational changes have been implemented such as the prioritization of virtual and telephone visits and the development of influenza vaccination campaigns in different spaces, outside the confines of health centres [6]. The lower degree of interaction with the healthcare system or the lack of specific and direct advice from a professional regarding vaccination appears to be related to the coverage achieved [11]. It remains to be seen how this limitation may have influenced the vaccine hesitancy and the management of indecision or doubts regarding vaccination this year.

With regard to the intention to be vaccinated against influenza this year during the SARS-CoV-2 pandemic, we found that an additional $5 \%$ coverage could be achieved with respect to the intention to vaccinate without considering this factor (question 12), a lower figure than that of the Goldman study, estimated at 10\% [13]. It is known that a negative attitude towards the influenza vaccine is associated with lower vaccination rates [11] and in this study it is noteworthy that, despite the ongoing pandemic, more than a third (34.8\%) of respondents reported that they would not be vaccinated regardless. These data would suggest a lack of awareness among the population regarding influenza, SARS-CoV-2 and their complications. They may also lack information regarding the risk of coinfection which, although such cases are rare, carry an increased risk for patients suffering from both infections. Hence the health authorities' preoccupation with actively encouraging influenza vaccinations this year. Recent evidence shows that mortality in patients with SARS-CoV-2 doubles when they are also infected with the influenza virus [21].

According to a Cochrane review [22] on the effectiveness of simple physical barriers in reducing the spread of respiratory viruses, frequent hand washing can reduce the transmission of respiratory viruses; isolation and physical barriers (wearing masks, gloves and gowns) did not show a clear reduction in respiratory viral infection; and there is insufficient evidence to show that physical distancing can reduce the spread of viruses. The results show that with regard to physical protection measures (masks, hand washing and spatial separation), more than $35 \%$ of the surveyed population would be willing to be vaccinated even though they believe that the barrier already protects them. That is, they are individuals who most likely already receive the seasonal influenza shot and who are not making an exception because of the pandemic. Meanwhile, it is significant that more than $10 \%$ of the participants believe that these three measures already protect them and therefore do not intend to be vaccinated. Finally, a significant percentage of participants expressed doubts regarding the intention to be vaccinated against influenza during the pandemic and the protection offered by contextual factors. Preventive 
measures are effective as they are taken together rather than being mutually exclusive or implemented independently. That is why in these groups it is important to improve the information to achieve a change in attitude regarding the acceptance of vaccination.

Therefore, although the intention to vaccinate group is not much larger than the non-intention group, there are many undecided individuals, possibly due to a lack of information, misconceptions or doubts, as in other studies [10]. Although not everyone is expected to change their vaccination intention and to go on to be vaccinated, it is necessary that medical professionals take the time to uncover their doubts and reluctance regarding vaccination, in order to be able to provide them with accurate information and help them make an informed decision [23]. A recent published paper of our group showed that a brief intervention could be an effective tool in improving vaccination coverage in reluctant people [24].

This study may present certain limitations. The finding of the study may not be totally generalizable as the study has been conducted in a specific region of Spain. It did not include individuals who had not given their consent to be contacted for healthcare and research purposes; this may have led to a certain selection bias, which we attempted to minimize through the randomization of participants. Although the questionnaire employed had been adapted from a previous one, some questions, especially those related to the intention to vaccinate during the SARS-CoV-2 pandemic, had very similar answer options which could generate doubts and be difficult to comprehend. A training session was held for the interviewers in order to control for these difficulties and avoid differences in the interpretation of the answers.

To continue with this line of research, the aim is to determine the relationship between vaccination intention with regard to influenza at the start of the vaccination campaign and the number of influenza vaccinations recorded at the end of the campaign in at-risk groups.

\section{Conclusions}

Vaccination intention can be a good predictor of people's future behaviour with regard to the influenza vaccination, although during the SARS-CoV-2 pandemic many people are undecided, possibly due to a lack of knowledge regarding influenza, its means of transmission and possible complications. This study highlights the need to strengthen health education regarding the influenza vaccination in at- risk groups, especially in those who express vaccine hesitancy.
Abbreviations

SIV: Seasonal Influenza Vaccine; WHO: World Health Organisation; ECDC: European Centre for Disease Prevention and Control; PCT: Primary Care teams; IDIAP: University Institut for Primary Care Research (Institut Universitari d'Investigació en Atenció Primària.

\section{Supplementary Information}

The online version contains supplementary material available at https://doi. org/10.1186/s12875-021-01434-8.

Additional file 1. Questionnaire.

\section{Acknowledgements}

We would like to thank Marisa Serra, Esperanza Solà, Judit Torrent and Lorena Vázquez for their support with the survey interviews.

\section{Authors' contributions}

ABE, RMM, CGC, AR and JVA contributed to the conceptualization, study design, data collection and writing of the article. XP contributed to the data analysis and writing of the article. All of the authors reviewed and approved the article prior to its publication.

Funding

None declared

\section{Availability of data and materials}

Our manuscript is based on confidential and sensitive healthcare data. However, to support scientific transparency, we have posted a de-identified and appropriately redacted data for replication purposes should you or the reviewers find it helpful. The data is available at the review stage for the journal staff and reviewers at our Mendeley data repository http://dx.doi.org/10.17632/9b4b43tr9k.1

\section{Declarations}

Ethics approval and consent to participate

All data extracted were anonymized and treated as strictly confidential. All methods were performed in accordance with the Declaration of Helsinki.The Research Ethics Committee (CEI) of the Institut Universitari d'Investigació en Atenció Primària (IDIAP Jordi Gol) approved the study protocol number 20/177-PCV.Verbal informed consent to participate was obtained from the participants previous to the telephone survey (it can be read in the Additional file 1 Questionnaire).

\section{Consent for publication}

Not applicable

\section{Competing interests}

The authors declare that they have no competing interests

\begin{abstract}
Author details
${ }^{1}$ Unitat de Farmàcia, Gerència Territorial Catalunya Central Institut Català de la Salut, Sant Fruitós de Bages, Spain. ${ }^{2}$ Health Promotion in Rural Areas Research Group, Gerència Territorial de la Catalunya Central, Institut Català de la Salut, Sant Fruitós de Bages, Spain. ${ }^{3}$ Centre d'Atenció Primària Plaça Catalunya, SAP Bages-Berguedà-Solsonès, Gerència Territorial Catalunya Central Institut Català de la Salut, CAP Plaça Catalunya. C/ Soler i March 6, 08242 Manresa, Spain. ${ }^{4}$ Centre d'Atenció Primària Vilanova del Camí, SAP Anoia, Gerència Territorial Catalunya Central, Institut Català de la Salut, Vilanova del Camí, Spain. ${ }^{5}$ Centre d'Atenció Primària Manlleu, SAP Osona, Gerència Territorial Catalunya Central, Institut Català de la Salut, Manlleu, Spain. ${ }^{6}$ Universitat Autònoma de Barcelona, Barcelona, Spain. ${ }^{7}$ Unitat de Suport a la Recerca de la Catalunya Central, Fundació Institut Universitari per a la recerca a I'Atenció Primària de Salut Jordi Gol i Gurina, Sant Fruitós de Bages, Spain. ${ }^{8}$ Faculty of Medicine, University of Vic Central University of Catalonia, Vic, Spain.
\end{abstract}

Received: 12 January 2021 Accepted: 26 March 2021

Published online: 01 May 2021 


\section{References}

1 Agència de Salut Pública de Catalunya. Departament de Salut. Generalitat de Catalunya. Programa de vacunacions. Guia tècnica per a la campanya de vacunació antigripal estacional 2019. Campanya 2019-20. Barcelona: ASPCAT; 2019 http://salutpublica.gencat.cat/web/.content/minisite/ aspcat/promocio_salut/vacunacions/06vacunacio-antigripal/informaciode-temporada/ASPCAT-GUIA-CAMPANYA-GRIP.pdf Accesed 11 Jan 2021

2 Ministerio de Sanidad Consumo y Bienestar Social. Gobierno de España. https://www.mscbs.gob.es/profesionales/saludPublica/prevPromocion/ vacunaciones/programasDeVacunacion/gripe/faq/Preguntas_respu estas_gripe_ciudadanos_2020-2021.htm. Accessed 11 Jan 2021.

3 European Centre for Disease Prevention and Control. Disease facts about seasonal influenza disease. https://www.ecdc.europa.eu/en/seasonalinfluenza/facts. Accessed 11 Jan 2021.

4 Lessler J, Reich NG, Brookmeyer R, Perl TM, Nelson KE, Cummings DA. Incubation periods of acute respiratory viral infections: a systematic review. Lancet Infect Dis. 2009;9:291-300. https://doi.org/10.1016/S14733099(09)70069-6.

5 World Health Organisation. Seasonal influenza. https://www.euro.who. int/en/health-topics/communicable-diseases/influenza/seasonal-influ enza. Accessed 11 Jan 2021.

6 Agència de Salut Pública de Catalunya. Departament de Salut. Generalitat de Catalunya. Vacunació antigripal. http://salutpublica.gencat.cat/web/. content/minisite/aspcat/promocio_salut/vacunacions/06vacunacioantigripal/informacio-de-temporada/0356_INTRANET-SSP-Recomanaci ons-vacunacio-antigripal-2020-2021.pdf. Accessed 3 Sept 2020.

7 World Health Organisation. Recommendations on influenza vaccination during the 2019-2020 winter season (2019). https://www.euro.who.int/ en/health-topics/communicable-diseases/influenza/publications/2019/ recommendations-on-influenza-vaccination-during-the-20192020-winter-season-2019. Accessed 3 Sept 2020.

8 Ministerio de Sanidad, Consumo y Bienestar Social. Coberturas de vacunación. Datos estadísticos. https://www.mscbs.gob.es/profesiona les/saludPublica/prevPromocion/vacunaciones/calendario-y-coberturas/ coberturas/historicoCoberturas.htm Accessed 11 Jan 2021.

9 Ministerio de Sanidad, Consumo y Bienestar Social. Gobierno de España. https://www.mscbs.gob.es/profesionales/saludPublica/prevPromocion/ vacunaciones/programasDeVacunacion/gripe/faq/Preguntas_respu estas_gripe_profsanitarios_2020-2021.htm\#Recomendaciones. Accessed 11 Jan 2021.

10 Zaraket H, Melhem N, Malik M, Khan W, Dbaibo G, Abubakar A. Review of seasonal influenza vaccination in the Eastern Mediterranean Region: policies, use and barriers. J Infect Public Health. 2020;13:377-84. https:// doi.org/10.1016/j.jiph.2020.02.029.

11 World Health Organisation. Barriers of influenza vaccination intention and behavior. A systematic review of influenza vaccine hesitancy 2005-2016. https://apps.who.int/iris/bitstream/handle/10665/251671/WHO-HIS-TTiGAP-16.2-eng.pdf. Accessed 3 Sept 2020.

12 Myers L, Goodwin R. Determinants of adults' intention to vaccinate against pandemic swine flu. BMC Public Health. 2011;11:1-5. https://doi. org/10.1186/1471-2458-11-15

13 Goldman R, McGregor S, Shashidar M, Katsuta T, Griffiths M, Hall J, et al. Willingness to vaccinate Children against Influenza after the COVID-19
Pandemic. J Pediatr. 2021;228:87-93. https://doi.org/10.1016/j.jpeds.2020. 08.005.

14 Generalitat de Catalunya. DECRET LLEI 27/2020, de 13 de juliol, de modificació de la Llei 18/2009, de 22 d'octubre, de salut pública, i d'adopció de mesures urgents per fer front al risc de brots de la COVID-19. https:// portaldogc.gencat.cat/utilsEADOP/PDF/8176/1804571.pdf. Accessed 11 Jan 2021.

15 Apiñaniz A, López-Picado A, Miranda-Serrano E, et al. Estudio transversal basado en la población sobre la aceptabilidad de la vacuna y la percepción de la gravedad de la gripe A/H1N1: Opinión de la población general y de los profesionales sanitarios. Gac Sanit. 2010;24(4):314-20. https://doi. org/10.1016/j.gaceta.2010.03.009.

16 Institut Municipal d'Investigació Mèdica. Sample size and power calculator. Version 7.12 April 2012. https://www.imim.cat/ofertadeserveis/softw are-public/granmo/. Accessed 20 Oct 2020.

17 Picazo J, González Romo F, Salleras Sanmartí J, Bayas Rodríguez J, Álvarez Pasquín M. Encuesta sobre la vacunación de adultos en España Gripe y neumococo. Vacunas. 2012;13(3):100-11. https://doi.org/10.1016/S15769887(12)70048-1.

18 Méijome-Blanco S, González-Cristobo G, Regueiro-Martínez AA. Análisis de la renuncia a la vacunación antigripal (Estudio REGRIVI). Semergen. 2018;44(6):395-9. https://doi.org/10.1016/j.semerg.2017.12.003.

19 Muñoz-Miralles R, Bonvehí Nadeu S, Sant Masoliver C, Martín Gallego A, Llamazares Robles MO, Mendioroz Peña J. Efectividad del consejo breve en la vacunación contra la gripe Estudio piloto en atención primaria. Vacunas. 2019;20(1):18-24. https://doi.org/10.1016/j.vacun.2019.01.001.

20 Nagata JM, Hernández-Ramos I, Kurup AS, Albrecht D, Vivas-Torrealba C, Franco-Paredes C. Social determinants of health and seasonal influenza vaccination in adults $\geq 65$ years: a systematic review of qualitative and quantitative data. BMC Public Health. 2013;13(1):388. https://doi.org/10. 1186/1471-2458-13-388.

21 Lacoboucci Gareth. Covid-19: Risk of death more than doubled in people who also had flu English data show. BMJ. 2020;370:m3720. https://doi. org/10.1136/bmj.m3720.

22 Jefferson T, Del Mar CB, Dooley L, Ferroni E, Al-Ansary LA, Bawazeer GA, VanDriel ML, Nair NS, Jones MA, Thorning S, Conly JM. Physical interventions to interrupt or reduce the spread of respiratory viruses. Cochrane Database Syst Rev. 2020;7:CD006207. https://doi.org/10.1002/14651858. CD006207.pub5.

23 Instituto de Salud Pública, 2006 Instituto de Salud Pública 2006 Gobierno de Navarra Instituto de Salud Pública, Sección de Promoción de la Salud Manual de Educación para la Salud. Pamplona

24 Muñoz-Miralles R, Bonvehí Nadeu S, Sant Masoliver C, Martín Gallego A, Gómez Del Canto J, Mendioroz Peña J, Bonet Esteve AM. Effectiveness of a brief intervention for acceptance of influenza vaccine in reluctant primary care patients. Gac Sanit. 2021;S0213-9111(21):00035-2. https:// doi.org/10.1016/j.gaceta.2021.01.002.

\section{Publisher's Note}

Springer Nature remains neutral with regard to jurisdictional claims in published maps and institutional affiliations.

Ready to submit your research? Choose BMC and benefit from

- fast, convenient online submission

- thorough peer review by experienced researchers in your field

- rapid publication on acceptance

- support for research data, including large and complex data types

- gold Open Access which fosters wider collaboration and increased citations

- maximum visibility for your research: over 100M website views per year

At BMC, research is always in progress.

Learn more biomedcentral.com/submissions 